\title{
Static quenching of ruthenium(II)-polypyridyl complexes by gallic acid and quercetin in aqueous and micellar media
}

\author{
Sheeba Daniel, G. Allen Gnana Raj* \\ Department of Chemistry and Research Centre, Scott Christian College (Autonomous), \\ Nagercoil - 629003, Tamil Nadu, India \\ *E-mail address: gallengraj@gmail.com
}

\begin{abstract}
The reactions of gallic acid and quercetin with the excited state $\mathrm{Ru}(\mathrm{II})$ complexes proceed through photoinduced electron transfer reaction in sodium dodecyl sulfate (SDS) and aqueous media at $\mathrm{pH} 11$ and has been studied by luminescence quenching technique. The static nature of quenching is confirmed from the ground state absorption studies in both the media. The observed quenching rate constant $\left(k_{\mathrm{q}}\right)$ values are sensitive to the nature of the ligand, medium and the structure of the quenchers. The electrostatic interaction of the cationic complexes with the anionic micelle reduces the $k_{\mathrm{q}}$ values in SDS compared to that in aqueous medium.
\end{abstract}

Keywords: Ru(II)-polypyridyl complex; Electron transfer; Quenching; Association constant

\section{INTRODUCTION}

Polyphenols are a class of phytochemicals found in high concentrations in wine, tea, grapes and a wide variety of other plants and have been associated with prevention of heart disease and cancer. The two main groups of polyphenols are flavonoids (quercetin) and phenolic acids (gallic acid). Phenolic acids are aromatic secondary plant metabolites, widely spread through the plant kingdom. The antioxidant effect of polyphenols can be due to both their radical-scavenging activity and to their metal-chelating properties, of which the former may dominate. In addition to antioxidant and free-radical scavenger properties, flavonoids also exhibit an inhibitory effect on a number of enzymes and potent anticancer effects [1]. The oxidation of phenols and polyphenols is of great interest because of their involvement in biochemical and industrial processes [2-4], the one electron oxidation of phenolates to the resulting phenoxyl radical is a key step in the oxidation of phenols. The study of the kinetic and thermodynamic aspects of electron transfer to generate phenoxyl radicals bearing bulky groups in the ortho and para- positions may help to understand the different biological roles of phenols.

Micelles mimic biosystems and are supramolecular aggregates that change the photophysical and photochemical behavior of probe molecules. These aggregates promote inclusion or exclusion of compounds, in the micelle core or at the micelle interface on the basis of hydrophobic and electrostatic interactions. It is well known that medium effects, such 
as solvent polarity, heterogeneity of the microenvironment and the addition of salts, have an important influence on the dynamics of photoinduced electron transfer (PET) between donor and acceptor in solution [5]. The interaction of transition metal complexes with surfactants continues to be of interest due to their applications in energy conversion and catalytic schemes and as tags for the analysis of species at low concentrations [6]. Photoinduced electron transfer reactions in surfactant solutions are potentially important for efficient energy conversion and storage because surfactant micelles help to achieve the separation of the photoproducts by hydrophilic-hydrophobic interactions of the products with the micellar interface $[7,8]$.

The $\mathrm{Ru}(\mathrm{II})$ polypyridyl complexes $\left(\left[\mathrm{Ru}(\mathrm{NN})_{3}\right]^{2+}\right.$ ) have been extensively used as probes in micellar media and the photophysical properties like emission maximum, excited state lifetime and emission quantum yield vary enormously with the nature of the surfactant and concentration. The presence of hydrophobic groups like alkyl or aryl in the 4,4'- position of 2,2'-bipyridine ligands leads to strong binding of $\left[\mathrm{Ru}(\mathrm{NN})_{3}\right]^{2+}$ with micelles through hydrophobic and electrostatic interactions, the strength of binding depends on the combination of electrostatic attractions or repulsions and hydrophobic effects [9-11]. Many researchers have attempted a systematic investigation of binding, partitioning and photosensitization of these $\left[\mathrm{Ru}(\mathrm{NN})_{3}\right]^{2+}$ complexes in both ionic and nonionic surfactant media [9-14]. In micellar solutions, reactions can be either accelerated or decelerated compared to the reactions in aqueous solutions without added co-solutes [15].

Investigations on the quenching efficiency of $\left[\mathrm{Ru}(\mathrm{NN})_{3}\right]^{2+}$ complexes with phenols have been made so far and the present study concentrates on the quenching behavior of $\left[\mathrm{Ru}(\mathrm{NN})_{3}\right]^{2+}$ complexes with gallic acid and quercetin in the absence and presence of sodium dodecyl sulfate (SDS) at $\mathrm{pH} 11$. The electronic absorption spectra validate the static nature of quenching that takes place in these PET reactions. The transient absorption spectra confirms the electron transfer nature of $\left[\mathrm{Ru}(\mathrm{NN})_{3}\right]^{2+}$ complexes with gallic acid and quercetin in both media at $\mathrm{pH} 11$.

\section{EXPERIMENTAL SECTION}

\section{1. Materials}

$\mathrm{RuCl}_{3} \cdot 3 \mathrm{H}_{2} \mathrm{O}$, ligands (2,2'-bipyridine (bpy), 4,4'-dimethyl-2,2'-bipyridine (dmbpy), 4,4'-di-tert-butyl-2,2'-bipyridine (dtbpy)) and the quenchers (gallic acid, quercetin) were procured from Sigma-Aldrich. HPLC grade solvents were used throughout the study for the synthesis of complex as well as for quenching studies. The double distilled deionized water was used for the quenching studies.

The three $\left[\mathrm{Ru}(\mathrm{NN})_{3}\right]^{2+}$ complexes $\left\{\right.$ where $\mathrm{NN}=2,2^{\prime}$-bipyridine (bpy), 4,4'-dimethyl2,2'-bipyridine (dmbpy), 4,4'-di-t-butyl-2,2'-bipyridine (dtbpy) $\}$ were synthesized by reacting $\mathrm{RuCl}_{3} \cdot 3 \mathrm{H}_{2} \mathrm{O}$ with the corresponding ligands according to the procedure previously described $[16,17]$. The chloride salt of $\left[\mathrm{Ru}(\mathrm{bpy})_{3}\right]^{2+}$ complex was treated with sodium tetrafluoroborate to get the $\mathrm{BF}_{4}^{-}$salt $\left[\mathrm{Ru}(\mathrm{bpy})_{3}\right]\left(\mathrm{BF}_{4}\right)_{2}$.

\section{2. Equipments}

Samples of the $\left[\mathrm{Ru}(\mathrm{NN})_{3}\right]^{2+}$ complexes, as well as the quenchers in $50 \%$ aqueous acetonitrile at $\mathrm{pH} 11$ were freshly prepared for each measurement. Absorption spectra were measured using SYSTRONICS 2203 double beam spectrophotometer. The emission spectra 
were recorded using ELICO SL 174 spectrofluorometer. All the sample solutions used for the emission and excited state lifetime measurements were deaerated for about $30 \mathrm{~min}$ by dry nitrogen gas purging keeping the solutions in cold water to ensure that there is no change in volume of the solution. All the spectral measurements were carried out at $293 \mathrm{~K}$. Excited state lifetime and transient absorption measurements were made with laser flash photolysis technique using an Applied Photophysics SP-Quanta Ray GCR-2(10) Nd:YAG laser as the excitation source [18]. The time dependence of the luminescence decay was observed using a Czerny-Turner monochromator with a stepper motor control and a Hamamatsu R-928 photomultiplier tube. The production of the excited state on exposure to $355 \mathrm{~nm}$ was measured by monitoring (pulsed Xenon lamp of $250 \mathrm{~W}$ ) the absorbance change. Transient spectra were obtained by a point-to-point technique, monitoring the absorbance changes $(\Delta \mathrm{A})$ after the flash at intervals of $10 \mathrm{~nm}$ over the spectral range $300-700 \mathrm{~nm}$, averaging at least 30 decays at each wavelength.

\section{3. Quenching studies}

The structures of the ligands and the quenchers used in the present study are shown in Fig. 1. The photochemical reduction of $\left[\mathrm{Ru}(\mathrm{NN})_{3}\right]^{2+}$ complexes with various concentrations $\left(2 \times 10^{-5}-1.4 \times 10^{-4} \mathrm{M}\right)$ of gallic acid and quercetin in the absence and presence of SDS $(0.01 \mathrm{M})$ at $\mathrm{pH} 11$ has been studied by luminescent quenching techniques.

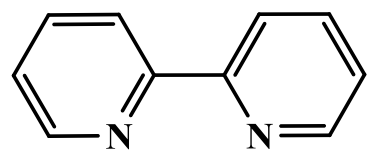

bpy

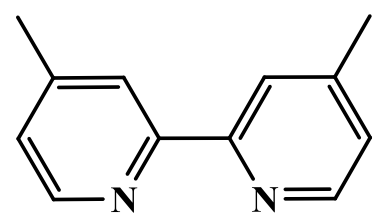

dmbpy

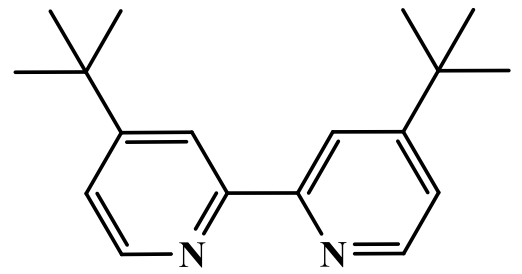

dtbpy<smiles>O=C(O)c1cc(O)c(O)c(O)c1</smiles>

Gallic acid<smiles>O=c1c(O)c(-c2ccc(O)c(O)c2)oc2cc(O)cc(O)c12</smiles>

Quercetin

Fig. 1. Structure of the ligands and the quenchers.

Phenolate ions of gallic acid and quercetin for the quenching studies were prepared by mixing the corresponding polyphenols with $\mathrm{NaOH}$ and the $\mathrm{pH}$ of the solution was maintained at 11 to confirm that the quencher was present as phenolate ions. 
The change of emission intensity of $*\left[\mathrm{Ru}(\mathrm{NN})_{3}\right]^{2+}$ with change of [Q] measured at 293 $\mathrm{K}$ is shown in Fig. 2. The quenching rate constant, $k_{\mathrm{q}}$, for the reaction was determined by the luminescence-quenching technique from the Stern-Volmer equation using emission intensity data [19].

$$
I_{O} / I=1+\boldsymbol{k}_{\mathbf{q}} \tau[\mathbf{Q}]
$$

where $I_{0}$ and $I$ are the emission intensities in the absence and presence of quencher respectively and $\tau$ is the emission lifetime of $\mathrm{Ru}$ (II) complexes in the absence of quencher. $\mathrm{A}$ sample Stern-Volmer plot for the luminescence quenching of $*\left[\mathrm{Ru}(\mathrm{NN})_{3}\right]^{2+}$ with polyphenol is shown in Fig. 3.

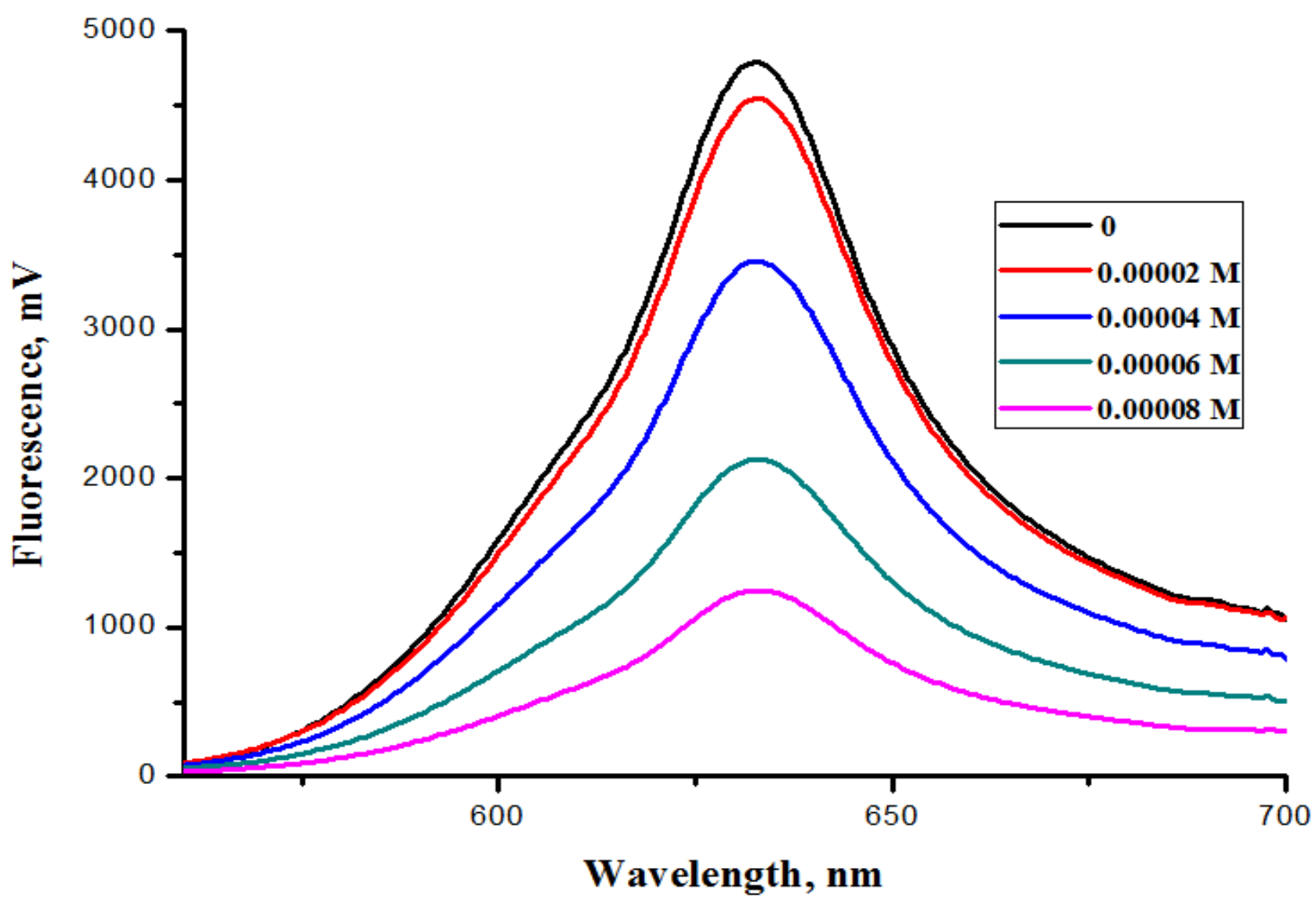

Fig. 2. The change in emission intensity of $*\left[\mathrm{Ru}(\mathrm{dtbpy})_{3}\right]^{2+}$ with different concentrations of gallic acid in SDS at $\mathrm{pH} 11$. 


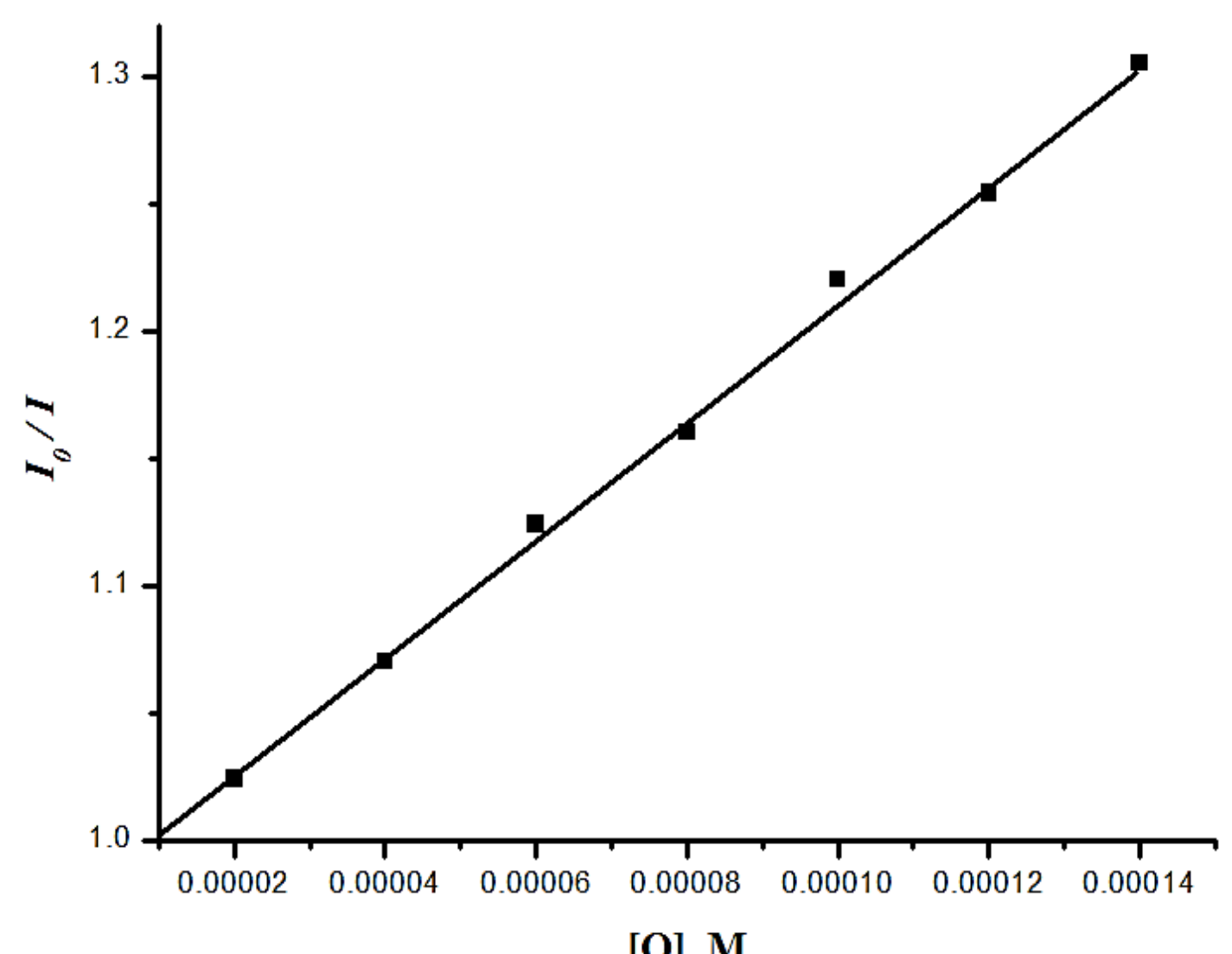

Fig. 3. Stern-Volmer plot for the reductive quenching of $*\left[\operatorname{Ru}(\text { bpy })_{3}\right]^{2+}$ with gallic acid in SDS at $\mathrm{pH} 11$.

\section{RESULTS AND DISCUSSION}

The absorption and emission spectral data, the excited state lifetime $(\tau)$ of the $\mathrm{Ru}(\mathrm{II})$ complexes in aqueous medium and in SDS at $\mathrm{pH} 11$ measured, are collected in Table 1. The values in the aqueous medium at $\mathrm{pH} 11$ are closely related to the reported values of the complexes in aqueous solution at $\mathrm{pH}>7$ [20].

The excited state lifetime of $*\left[\mathrm{Ru}\left(\mathrm{NN}_{3}\right)\right]^{2+}$ complexes are highly sensitive to the change of medium.

The lifetime of the Ru(II)-polypyridyl complexes in SDS are longer than those in aqueous solution, mainly due to electrostatic interactions of cationic Ru(II) complexes with the surface of the anionic micelle.

Because of this binding, the excited state complex will be shielded to some extent from the exposure of the solvent water molecules.

The bimolecular quenching rate constant $\left(k_{\mathrm{q}}\right)$ for the reductive quenching of three $\mathrm{Ru}(\mathrm{II})$ complexes $*\left[\mathrm{Ru}(\mathrm{bpy})_{3}\right]^{2+}, *\left[\mathrm{Ru}(\mathrm{dmbpy})_{3}\right]^{2+}$ and $*\left[\mathrm{Ru}(\mathrm{dtbpy})_{3}\right]^{2+}$ with the phenolate ions of gallic acid and quercetin at pH 11 in aqueous and SDS media are given in Table 2. 
Table 1. Absorption and emission spectral data and excited state lifetime of $\left[\mathrm{Ru}(\mathrm{NN})_{3}\right]^{2+}$ complexes in aqueous and SDS media at $\mathrm{pH} 11$.

\begin{tabular}{ccccccc}
\hline \multirow{2}{*}{ Complex } & \multicolumn{2}{c}{$\begin{array}{c}\text { Absorption maximum } \\
(\mathrm{nm})\end{array}$} & $\begin{array}{r}\text { Emission maximum } \\
(\mathrm{nm})\end{array}$ & \multicolumn{2}{c}{$\begin{array}{r}\text { Excited state lifetime } \\
(\mathrm{ns})\end{array}$} \\
\cline { 2 - 7 } & Aqueous & SDS & Aqueous & SDS & Aqueous & SDS \\
\hline$\left[\mathrm{Ru}(\mathrm{bpy})_{3}\right]^{2+}$ & $451(452)$ & 445 & $612(613)$ & 628 & $614(620)$ & 740 \\
{$\left[\mathrm{Ru}(\mathrm{dmbpy})_{3}\right]^{2+}$} & $457(460)$ & 450 & $625(630)$ & 639 & $380(330)$ & 530 \\
{$\left[\mathrm{Ru}(\mathrm{dtbpy})_{3}\right]^{2+}$} & $457(456)$ & 456 & 626 & 633 & 510 & 760 \\
\hline
\end{tabular}

The values in the parenthesis represent the reported absorption maximum, emission maximum and excited state life time of $\mathrm{Ru}$ (II) complexes in aqueous medium at $\mathrm{pH}>7$, ref. [20].

Table 2. Quenching rate constant, $k_{\mathrm{q}}$, values for the reductive quenching of $\left[\mathrm{Ru}(\mathrm{NN})_{3}\right]^{2+}$ by the phenolate ions of gallic acid and quercetin in aqueous and SDS media at $\mathrm{pH} 11$.

\begin{tabular}{ccccc}
\hline \multirow{2}{*}{ Complex } & \multicolumn{4}{c}{ Quenching rate constant, $k_{\mathrm{q}}\left(\mathrm{M}^{-1} \mathrm{~s}^{-1}\right)$} \\
\cline { 2 - 5 } & \multicolumn{2}{c}{ Aqueous } & \multicolumn{2}{c}{ SDS } \\
\cline { 2 - 5 } & Gallic acid & Quercetin & Gallic acid & Quercetin \\
\hline$\left[\mathrm{Ru}(\mathrm{bpy})_{3}\right]^{2+}$ & $8.8 \times 10^{9}$ & $6.3 \times 10^{9}$ & $2.9 \times 10^{9}$ & $9.2 \times 10^{8}$ \\
{$\left[\mathrm{Ru}(\mathrm{dmbpy})_{3}\right]^{2+}$} & $7.1 \times 10^{9}$ & $4.6 \times 10^{9}$ & $9.6 \times 10^{8}$ & $7.5 \times 10^{8}$ \\
{$\left[\mathrm{Ru}(\mathrm{dtbpy})_{3}\right]^{2+}$} & $6.0 \times 10^{9}$ & $3.5 \times 10^{9}$ & $6.8 \times 10^{8}$ & $4.6 \times 10^{8}$ \\
\hline
\end{tabular}

The absorption spectral studies of $\left[\mathrm{Ru}(\mathrm{bpy})_{3}\right]^{2+},\left[\mathrm{Ru}(\mathrm{dmbpy})_{3}\right]^{2+}$ and $\left[\mathrm{Ru}(\mathrm{dtbpy})_{3}\right]^{2+}$ complexes with the incremental addition of gallic acid and quercetin $\left(2 \times 10^{-5}-1.4 \times 10^{-4} \mathrm{M}\right)$ in both media show a slight increase in the MLCT absorption maximum, indicates the formation of ground state complex (Fig. 4). The association of gallic acid and quercetin with $\left[\mathrm{Ru}(\mathrm{NN})_{3}\right]^{2+}$ complexes in the ground state may be due to the static nature of quenching in both media at $\mathrm{pH} 11$. Though the Stern-Volmer plots are linear for the reductive quenching of $\left[\mathrm{Ru}(\mathrm{NN})_{3}\right]^{2+}$ complexes with gallic acid and quercetin (Fig. 3), absorption spectral studies and the corresponding association constant values (Table 3) in aqueous and SDS media confirm the static nature of quenching.

Gallic acid consist of three phenolic-OH groups, in alkaline medium especially above $\mathrm{pH} 9$ the three phenolic-OH groups get ionized. The $\mathrm{p} K_{\mathrm{a}}$ values for the three phenolic-OH 
groups of gallic acid are 8.7, 11.4 and $>13$ [21]. Quercetin has two different pharmacophores, the catechol group in ring B and the three hydroxyl groups in rings A and $\mathrm{C}$, of which the catechol moiety is the most reactive one where deprotonation occurs easily [22]. The $\mathrm{p} K_{\mathrm{a}}$ values of quercetin are 5.87 and 8.48 [23]. The $\mathrm{p} K_{\mathrm{a}}$ values of the quenchers taken in the present study are less than that on the $\mathrm{pH}$ of the medium ( $\mathrm{pH} 11)$, hence they undergo PET reactions with the $*\left[\mathrm{Ru}(\mathrm{NN})_{3}\right]^{2+}$ complexes in aqueous and SDS media.

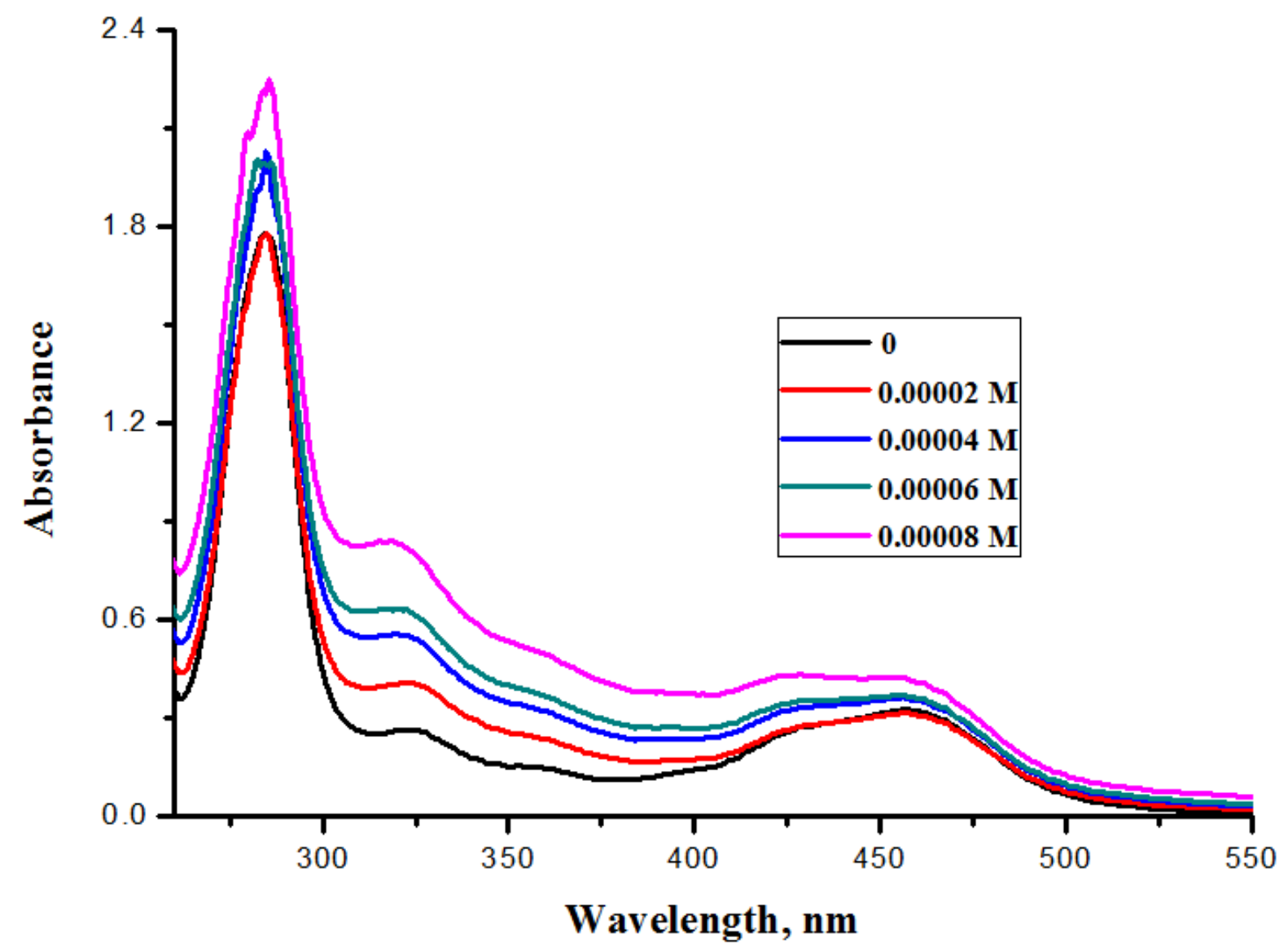

Fig. 4. Absorption spectra of $\left[\mathrm{Ru}(\mathrm{dmbpy})_{3}\right]^{2+}$ with incremental addition of quercetin in SDS at $\mathrm{pH} 11$.

The $k_{\mathrm{q}}$ data in Table 2 shows that gallic acid act as the efficient quencher in these PET reactions. The quenching rate constant increases, when the number of phenolic-OH groups present in the quencher increases.

Here gallic acid has three phenolic-OH groups, while quercetin has four phenolic-OH groups ( 2 phenolic-OH groups in ring $\mathrm{B}$ and 2 phenolic-OH groups in ring $\mathrm{A}$ ) out of these the ring $\mathrm{B}$ is the most reactive one. Hence gallic acid acts as the efficient quencher in this photoredox system due to the presence of pyrogallol moiety. The pyrogallol moiety is more reactive than catechol moiety [24]. 
Table 3. Association constant, $K_{\mathrm{a}}\left(\mathrm{M}^{-1}\right)$ from absorption spectral data for gallic acid and quercetin with $\left[\mathrm{Ru}(\mathrm{NN})_{3}\right]^{2+}$ complexes in aqueous and SDS at $\mathrm{pH} 11$.

\begin{tabular}{ccccc}
\hline \multirow{2}{*}{ Complex } & \multicolumn{2}{c}{ Aqueous } & \multicolumn{2}{c}{ SDS } \\
\cline { 2 - 5 } & Gallic acid & Quercetin & Gallic acid & Quercetin \\
\hline$\left[\mathrm{Ru}(\mathrm{bpy})_{3}\right]^{2+}$ & $2.9 \times 10^{3}$ & $4.0 \times 10^{4}$ & $1.0 \times 10^{2}$ & $1.9 \times 10^{3}$ \\
{$\left[\mathrm{Ru}(\mathrm{dmbpy})_{3}\right]^{2+}$} & $8.2 \times 10^{3}$ & $5.7 \times 10^{4}$ & $3.1 \times 10^{2}$ & $2.7 \times 10^{3}$ \\
{$\left[\mathrm{Ru}(\mathrm{dtbpy})_{3}\right]^{2+}$} & $8.9 \times 10^{3}$ & $9.0 \times 10^{4}$ & $4.7 \times 10^{2}$ & $4.3 \times 10^{3}$ \\
\hline
\end{tabular}

The presence of $0.01 \mathrm{M}$ anionic micelle lowers the $k_{\mathrm{q}}$ of $\left[\mathrm{Ru}(\mathrm{bpy})_{3}\right]^{2+},\left[\mathrm{Ru}(\mathrm{dmbpy})_{3}\right]^{2+}$ and $\left[\mathrm{Ru}(\mathrm{dtbpy})_{3}\right]^{2+}$ complexes. The reason for this lowering is due to the binding of cationic complexes $\left[\mathrm{Ru}(\mathrm{NN})_{3}\right]^{2+}$ to the anionic micelle mainly through electrostatic interactions apart from the hydrophobic interactions. Due to these interactions, only one - third of the sensitizers are exposed outside on micellization and the exposed fraction decreases with increase in the hydrophobic nature of the sensitizer.

The $k_{\mathrm{q}}$ depends on the electron transfer (ET) distance between the complex and the quencher. The $k_{\mathrm{q}}$ of the $\mathrm{Ru}(\mathrm{II})$ complexes with gallic acid and quercetin decreases from $\left[\mathrm{Ru}(\mathrm{bpy})_{3}\right]^{2+}$ to $\left[\mathrm{Ru}(\mathrm{dtbpy})_{3}\right]^{2+}$ in both media, due to the presence of the hydrophobic alkyl groups in the ligand. The introduction of bulky ligand increases the size of the reactant and thus the distance of ET, which affects the rate of ET. The ET distance of $\left[\mathrm{Ru}(\mathrm{bpy})_{3}\right]^{2+}$, $\left[\mathrm{Ru}(\mathrm{dmbpy})_{3}\right]^{2+}$ and $\left[\mathrm{Ru}(\mathrm{dtbpy})_{3}\right]^{2+}$ complexes with gallic acid in both media are $11.2,12$ and $13.3 \AA$, whereas for quercetin are $13.03,13.83$ and $15.13 \AA$ respectively. Here the ET distance for gallic acid is less compared to that of quercetin, this result in higher $k_{\mathrm{q}}$ value for gallic acid in both media.

The reductive quenching of $\left[\mathrm{Ru}(\mathrm{NN})_{3}\right]^{2+}$ complexes by the phenolate ions of polyphenols have been confirmed from the transient absorption spectra. The band at $510 \mathrm{~nm}$ in the transient absorption spectra of the $\left[\mathrm{Ru}(\mathrm{bpy})_{3}\right]^{2+}$ complex with $8 \times 10^{-5} \mathrm{M}$ gallic acid (Fig. 5) confirms the reductive nature $\left(\left[\mathrm{Ru}(\mathrm{bpy})_{3}\right]^{+}\right)$of the complex. The behavior of these redox systems can be discussed by a common mechanism depicted in Scheme 1.

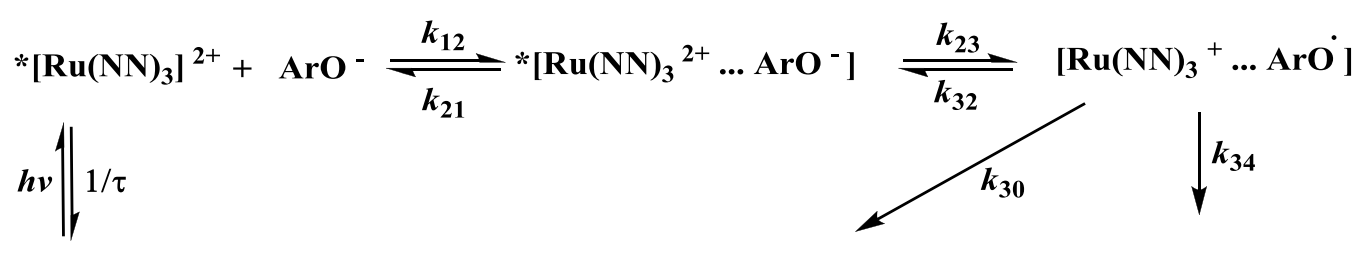

$$
\left[\mathrm{Ru}(\mathrm{NN})_{3}\right]^{2+}+\mathrm{ArO}^{-} \longleftarrow\left[\mathrm{Ru}(\mathrm{NN})_{3}{ }^{2+} \ldots \mathrm{ArO}^{-}\right] \quad\left[\mathrm{Ru}(\mathrm{NN})_{3}\right]^{+}+\operatorname{ArO}
$$

Scheme 1. Mechanism for the electron transfer quenching of $*\left[\mathrm{Ru}(\mathrm{NN})_{3}\right]^{2+}$ with $\mathrm{ArO}^{-}$.

The reactants diffuse together to form the encounter complex at the closest distance of approach. The electron transfer occurs in this association complex $\left[{ }^{*} \mathrm{Ru}(\mathrm{NN})_{3}{ }^{2+} \ldots \mathrm{ArO}\right]$ 
resulting in the formation of a caged pair of radicals or radical ions. The radical ions either escape from the solvent cage to give the redox products or undergo back electron transfer leading to the formation of the original reactants.

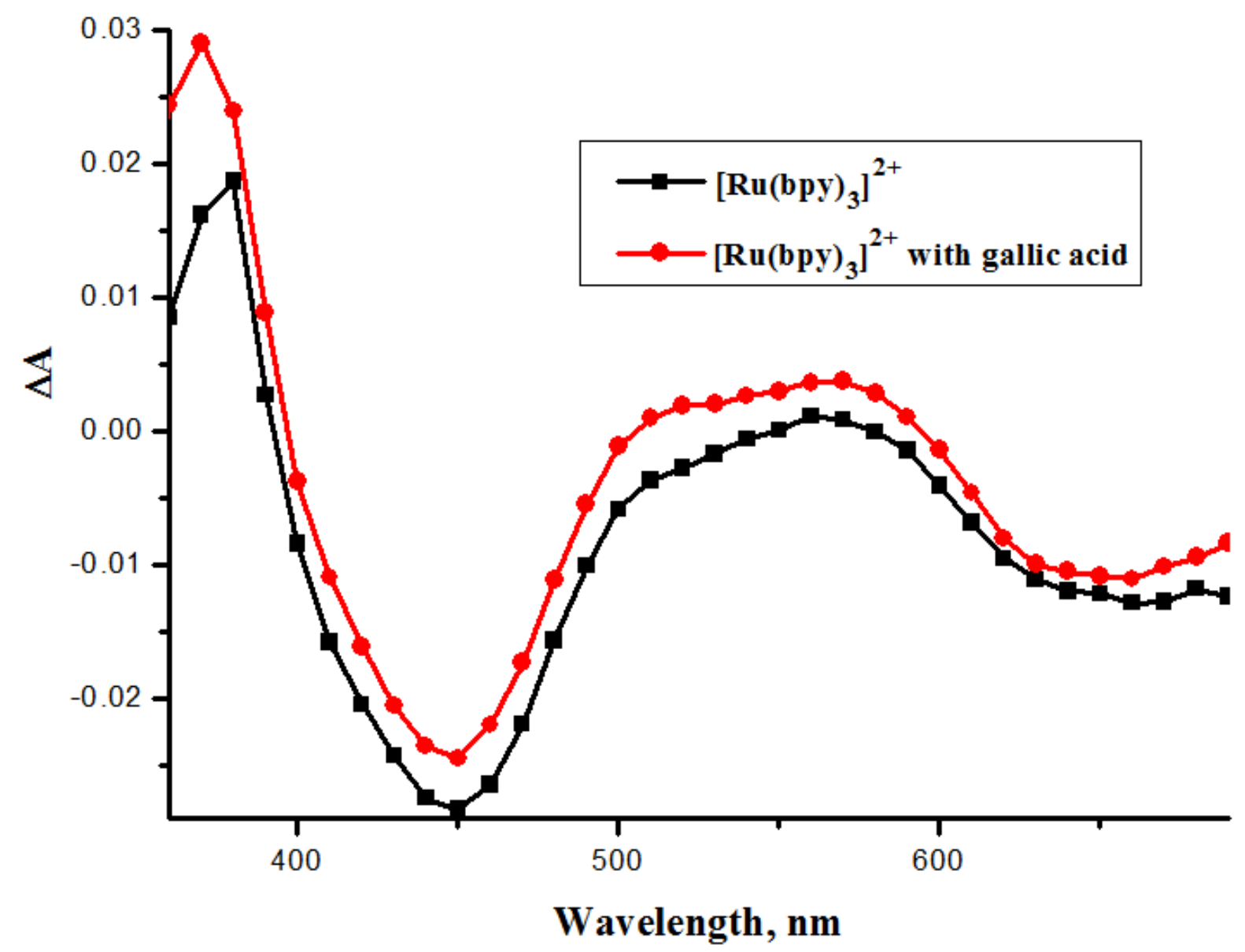

Fig. 5. Transient absorption spectra of $*\left[\mathrm{Ru}(\mathrm{bpy})_{3}\right]^{2+}$ in the absence and presence of $8 \times 10^{-5} \mathrm{M}$ gallic acid in SDS ( $\mathrm{pH} 11)$ recorded at $100 \mathrm{~ns}$.

\section{CONCLUSIONS}

The present study clearly establishes the reductive nature of the $*\left[\mathrm{Ru}(\mathrm{NN})_{3}\right]^{2+}$ complexes with gallic acid and quercetin in aqueous and SDS at $\mathrm{pH}$ 11. Absorption spectral studies and the association constant data confirm the static nature of quenching in both media. The $k_{\mathrm{q}}$ values are sensitive to the nature of the ligand, medium and the structure of the quenchers. SDS results in low quenching rate constant compared to that in aqueous medium at $\mathrm{pH} 11$ due to the electrostatic interactions of the cationic complexes with the anionic micelle. The study confirms the steric and electrostatic interactions on the electron transfer reactions of biologically important phenolate ions with the excited state $\mathrm{Ru}(\mathrm{II})$ complexes. 


\section{ACKNOWLEDGMENT}

One of the authors Sheeba Daniel thanks the Council of Scientific and Industrial Research (CSIR), New Delhi, India for the award of Senior Research Fellowship and Prof. P. Ramamurthy, Director, National Centre for Ultrafast Processes, University of Madras, Chennai for the permission granted to do the lifetime measurements.

\section{References}

[1] A. M. O. Brett, M. E. Ghica, Electroanalysis 15 (2003) 1745-1750.

[2] M. H. V. Huynh, T. J. Meyer, Chem. Rev. 107 (2007) 5004-5064.

[3] C. J. P. Monteiro, et al., Photochem. Photobiol. Sci. 4 (2005) 617-624.

[4] A. Altamirano, A. Senz, H. E. Gsponer, J. Colloid. Interface Sci. 270 (2004) 364-370.

[5] P. Thanasekaran, J. Y. Wu, B. Manimaran, T. Rajendran, I. J. Chang, S. Rajagopal, G. H. Lee, S. M. Peng, K. L. Lu, J. Phys. Chem. A 111 (2007) 10953-10960.

[6] W. Scott, M. R. Mark, Anal. Chem. 72 (2000) 5556-5561.

[7] M. Grätzel, Inorg. Chem. 44 (2005) 6841-6851.

[8] G. J. Meyer, Inorg. Chem. 44 (2005) 6852-6864.

[9] A. Jain, W. Xu, J. N. Demas, B. A. DeGraff, Inorg. Chem. 37 (1998) 1876-1879.

[10] W. J. Dressick, J. Cline, J. N. Demas, B. A. DeGraff, J. Am. Chem. Soc. 108 (1986) 7567-7574.

[11] S. W. Synder, D. E. Raines, P. T. Rieger, J. N. Demas, B. A. Degraff, Langmuir 1 (1985) 548-552.

[12] F. H. Quina, E. A. Lissi, Acc. Chem. Res. 37 (2004) 703-710.

[13] M. I. Gutiérrez, C. G. Martínez, D. García-Fresnadillo, A. M. Castro, G. Orellana, A. M. Braun, E. Oliveros, J. Phys. Chem. A 107 (2003) 3397-3403.

[14] T. Chakraborty, S. Ghosh, S. P. Moulik, J. Phys. Chem. B 109 (2005) 14813-14823.

[15] L. Onel, N. J. Buurma, J. Phys. Chem. B 115 (2011) 13199-13211.

[16] B. Saha, D. M. Stanbury, Inorg. Chem. 39 (2000) 1294-1300.

[17] T. Rajendran, S. Rajagopal, C. Srinivasan, P. Ramamurthy, J. Chem. Soc. Faraday Trans. 93 (1997) 3155-3160.

[18] P. Ramamurthy, Chem. Educ. 9 (1993) 56-60.

[19] J. R. Lakowicz, Principles of Fluorescence Spectroscopy, 3rd edn. Springer Press, New York, 2006.

[20] K. Kalyanasundaram, Photochemistry of polypyridine and porphyrin complexes. Academic Press, London, 1992.

[21] M. Can, E. Bulut, M. Ozacar, Ind. Eng. Chem. Res. 51 (2012) 6052-6063.

[22] P. Trouillas, P. Marsal, D. Siri, R. Lazzaroni, J. L. Duroux, Food Chem. 97 (2006) 679688. 
[23] C. S. Harris, F. Mo, L. Migahed, L. Chepelev, P. S. Haddad, J. S. Wright, W. G. Willmore, J. T. Arnason, S. A .L. Bennett, Can. J. Physiol. Pharmacol. 85 (2007) 1124-1138.

[24] A. Mohd, K. Haruo, S. Shiro, J. Anal. Appl. Pyrolysis 92 (2011) 76-87. 